\title{
Sex Prediction From Metrical Analysis of Macerated Mandibles of Brazilian Adults
}

\author{
Predicción Sexual Mediante Análisis Métrica de Mandíbulas Maceradas de Brasileños Adultos
}

\author{
N. Alves ${ }^{1,2} \&$ N. F. Deana ${ }^{3}$
}

ALVES, N. \& DEANA, N. F. Sex prediction from metrical analysis of macerated mandibles of Brazilian adults. Int. J. Morphol., 37(4):1375-1381, 2019.

SUMMARY: Determining sex may be more difficult in cases such as natural disasters, accidents or situations in which bodies are subjected to high temperatures, when individuals must be identified from their remains. The mandible is a very strong bone, presents high sexual dimorphism and may be useful in forensic identification. The object of the present study was to determine sex by metrical analysis of macerated mandibles of Brazilian adults. We analysed 113 fully dentate macerated mandibles of Brazilian adults, 47 belonging to women and 66 to men. We took 8 measurements using a digital calliper: bicondilar breadth (BC), bigonial breadth (BG), bimental foramina breadth (BM), distance between mental foramen and mandibular base (MF-MB), mandibular ramus height (MRH), maximum mandibular ramus breadth (MaRB), minimum mandibular ramus breadth (MiRB) and mandibular body length (MBL). The $t$ test was used for statistical analysis of independent samples, and a ROC curve was constructed. Direct and stepwise discriminant analysis was carried out. SPSS v.22 software was used, with a significance threshold of $5 \%$. We observed that all the measurements presented statistically significant differences between the sexes, with greater mean values for men than for women. BG was the measurement which presented the greatest area under curve (AUC), and the highest correct prediction, followed by MRH and BC. The BM distance presented the smallest AUC and lowest correct prediction. The mean correct prediction was $85 \%$ for direct discriminant analysis and $83.2 \%$ for stepwise discriminant analysis, using the BG and MRH measurements. The measurements analysed in this study can be used to determine the sex of Brazilian individuals.

KEY WORDS: Mandible; Sexual prediction; Discriminant analysis.

\section{INTRODUCTION}

The principal characteristics of biological identity are sex, age, stature and ethnic origin (Scheuer, 2002). Determining sex is important for forensic anthropology when an unknown individual needs to be identified. Determining sex may be more difficult in cases such as natural disasters, accidents or situations in which bodies are subjected to high temperatures, when individuals must be identified from their remains. The cranium (including the mandible) and the pelvis are considered to be the structures presenting the greatest sexual dimorphism (Sharma et al., 2016), with accuracies of $92 \%$ and $95 \%$ respectively (Krogman \& Iscan, 1986). The mandible is a bone which forms the lower third of the face (Alves \& Cândido, 2016). It is a very important structure for determining sex as it is very strong and presents high sexual dimorphism (Ongkana \& Sudwan, 2009).
Some studies have analysed the morphological characteristics of the mandible, observing that the ramus flexure (Kemkes-Grottenthaler et al., 2002; Saini et al., 2011), gonial eversion (Kemkes-Grottenthaler et al.) and shape of the chin (Deana \& Alves, 2017) present important sexual dimorphism. However, sexual dimorphism can be more accurately assessed by anthropometric methods, since classification by visual analysis may be more subjective, varying between researchers (Ogawa et al., 2013). Morphological features may present variation between different populations; factors such as socio-economic status, environmental and climatic effects, genetic composition, nutritional state and diet may result in some features being more or less accentuated in a given population (Angel, 1976; Krogman \& Iscan; Rogers, 2005; Oettlé et al., 2009; Evteev

\footnotetext{
${ }^{1}$ Centro de Investigación en Morfología Aplicada (CIMA), Faculty of Dentistry, Universidad de La Frontera, Temuco, Chile.

${ }^{2}$ Centro de Excelencia en Estudios Morfológicos y Quirúrgicos (CEMyQ), Faculty of Medicine, Universidad de La Frontera, Temuco, Chile.

${ }^{3}$ Center for Research in Epidemiology, Economics and Oral Public Health (CIEESPO), Faculty of Dentistry, Universidad de La Frontera, Temuco, Chile.
} 
et al., 2014). It is therefore, important to carry out anthropometric studies in every population in order to have up-to-date information available to aid anthropologists and forensic investigators in determining the sex of an individual. The objective of the present study was to determine sex by metrical analysis of macerated mandibles of Brazilian adults.

\section{MATERIAL AND METHOD}

Sample: In the present study we analysed 113 fully dentate macerated mandibles of Brazilian adults, 47 belonging to women and 66 to men. They belonged to the Department of Morphology and Genetics, UNIFESP (Brazil). Mandibles for which there was no information on sex or nationality, those which were partially or completely edentate, and those which were damaged or presented any kind of pathology were excluded from the study.

The researchers were calibrated prior to carrying out the measurements. The following measurements were taken with a digital calliper: bicondilar breadth, bigonial breadth, bimental foramina breadth, distance between mental foramen and mandibular base, mandibular ramus height, maximum mandibular ramus breadth, minimum mandibular ramus breadth and mandibular body length (Table I).

Statistical analysis: Descriptive analysis was by mean value with standard deviation. Measurements were compared using a t test for independent samples. We constructed a ROC curve to analyse the best diagnostic test. We carried out direct and stepwise discriminant analysis and a Fisher discrimination analysis. The discriminant function was obtained for the female and male sexes as follows: Sex $=$ constant $+(\mathrm{r} 1 \times$ $\mathrm{m} 1)+\left(\mathrm{r}^{2} \times \mathrm{m}^{2}\right)+\left(\mathrm{r}^{3} \times \mathrm{m}^{3}\right) \ldots$, where $\mathrm{r}$ is the discriminant coefficient and $\mathrm{m}$ is the discriminant variable (mandible measurements). In this model, the measurements can be substituted in the 2 functions and the results compared. The diagnosis was carried out as follows: female $>$ male $=$ male; female $<$ male $=$ female; and female $=$ male, sex not defined The SPSS v.22 software was used, with a significance threshold of $5 \%$.

Table I. Description and abbreviations of the measurements analysed.

\begin{tabular}{lll}
\hline Measurement & Description & Abbreviation \\
\hline Bicondilar breadth & Distance between the two lateral condylion & BC \\
Bigonial breadth & Distance between right and left gonion & BG \\
Bimental foramina breadth & Distance between the two mental foramina & BM \\
Distance between mental foramen and & The shortest distance from the inferior marg in of mental foramen to the & MF-MB \\
mandibular base & mandibular base & The distance from the highest point on the mandibular condyle to the \\
Mandibular ramus height & gonion & MRH \\
Maximum mandibular ramus breadth & The maximum anteroposterior distance of the mandibular ramus & MaRB \\
Minimum mandibular ramus breadth & The minimum anteroposterior distance of the mandibular ramus & MiRB \\
Mandibular body length & Linear distance between gonion and gnathion & MBL \\
\hline
\end{tabular}

\section{RESULTS}

We observed that all the measurements presented statistically significant differences between the sexes, with greater mean values for males than for females (Table II). No statistical differences were found between sides, therefore the measurements were analysed together using the ROC curve.

BG was the distance presenting the greatest area under curve (AUC) (Fig. 1) (Table III), with good accuracy and the best balance between sensitivity and specificity, followed by $\mathrm{MRH}$ and $\mathrm{BC}$. All the other measurements presented AUC of less than 0.700. The BM distance presented the smallest AUC and lowest sensitivity (Fig. 1)

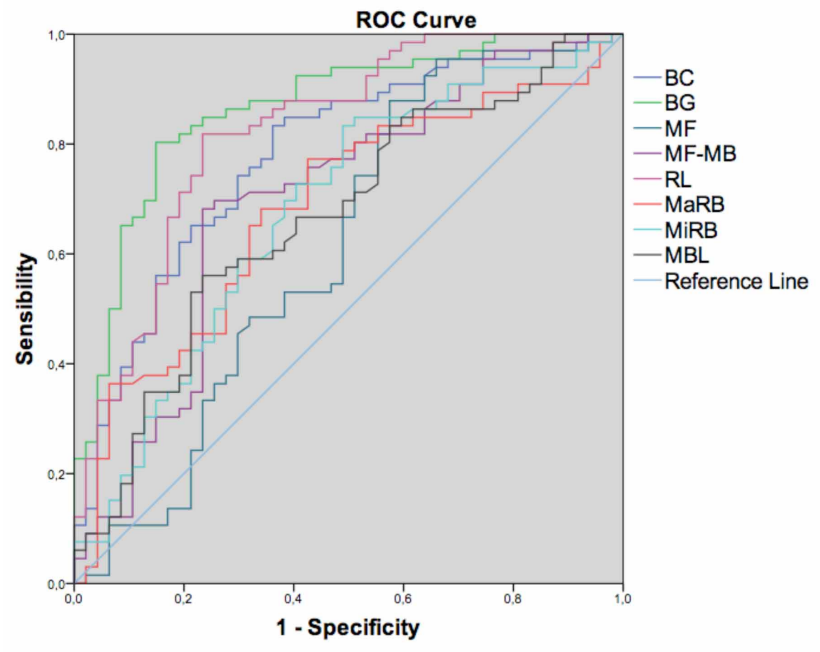

Fig. 1. ROC curve for the measurements analysed. 
(Table III). Table III shows the cut-off point (PC), representing the ideal point for sex determination for each measurement analysed in the mandible.

We observed through discriminant analysis that the measurement offering the best prediction of sex was BG $(80.5 \%)$, followed by MRH (76.1\%), BC (69.9\%) and
MiRB (66.8\%). BM was the measurement which presented the poorest sex prediction (55.8\%) (Table IV). Direct discriminant analysis presented $85.0 \%$ mean correct prediction; stepwise analysis presented $83.2 \%$ mean correct prediction using the BG and MRH measurements (Table $\mathrm{V})$. Table $\mathrm{V}$ shows the discriminant function generated for each sex.

Table II. Mean values (in millimetres), standard deviation (SD), Confidence interval (CI) and p-value of the measurements analysed, by sex and side.

\begin{tabular}{llllcc}
\hline Measurement & Sex & Mean & SD & CI $(95 \%)$ & p-value \\
\hline BC & Males & 118.84 & 5.59 & $-7.49-3.47$ & 0.00 \\
& Females & 113.35 & 4.88 & & \\
BG & Males & 96.38 & 5.19 & $-10.03-6.14$ & 0.000 \\
BM & Females & 88.29 & 5.07 & & \\
& Males & 44.11 & 2.28 & $-2.20-0.09$ & 0.032 \\
MF-MB & Females & 42.93 & 3.36 & & \\
& Males & 13.83 & 1.49 & $-1.25-0.45$ & 0.000 \\
MRH & Females & 12.97 & 1.51 & & \\
& Males & 62.26 & 4.35 & $-7.41-4.83$ & 0.000 \\
MaRB & Females & 56.13 & 5.16 & & \\
& Males & 43.21 & 4.41 & $-3.52-0.84$ & 0.002 \\
MiRB & Females & 41.03 & 5.41 & & \\
& Males & 31.45 & 3.24 & $-3.12-1.25$ & 0.000 \\
MBL & Females & 29.26 & 3.68 & & \\
& Males & 85.34 & 4.64 & $-4.49-1.98$ & 0.000 \\
\hline
\end{tabular}

Table III. Analysis of the ROC curve for the measurements taken in the mandible.

\begin{tabular}{lclccc}
\hline Measurement & AUC & \multicolumn{1}{c}{ CP } & A & SS & SP \\
\hline BC & 0.778 & females $<114.260>$ males & $75.2 \%$ & $63.8 \%$ & $83.3 \%$ \\
BG & 0.865 & females $<92.920>$ males & $82.3 \%$ & $85.1 \%$ & $80.3 \%$ \\
BM & 0.613 & females $<41.750>$ males & $69.0 \%$ & $42.6 \%$ & $87.9 \%$ \\
MF-MB & 0.698 & females $<13.430>$ males & $71.7 \%$ & $76.6 \%$ & $68.2 \%$ \\
MRH & 0.824 & females $<59.080>$ males & $79.6 \%$ & $76.6 \%$ & $81.8 \%$ \\
MaRB & 0.684 & females $<40.360>$ males & $69.0 \%$ & $57.4 \%$ & $77.3 \%$ \\
MiRB & 0.680 & females $<30.802>$ males & $68.7 \%$ & $58.2 \%$ & $76.5 \%$ \\
MBL & 0.666 & females $<85.150>$ males & $76.6 \%$ & $56.1 \%$ & $55.4 \%$ \\
\hline
\end{tabular}

AUC, Area under curve; CP, Cut-off point; A, Accuracy; SS, Sensitivity; SE, Specificity.

Table IV. Discriminant analysis of measurements analysed.

\begin{tabular}{lcccc}
\hline Measurement & $\lambda$ Wilks & \multicolumn{2}{c}{ Correct prediction } & Mean correct \\
& & Males & Females & prediction \\
\hline BC & 0.791 & $68.2 \%$ & $72.3 \%$ & $69.9 \%$ \\
BG & 0.620 & $80.3 \%$ & $80.9 \%$ & $80.5 \%$ \\
BM & 0.959 & $59.1 \%$ & $40.9 \%$ & $55.8 \%$ \\
MF-MB & 0.927 & $60.6 \%$ & $69.1 \%$ & $64.2 \%$ \\
MRH & 0.707 & $77.3 \%$ & $74.5 \%$ & $76.1 \%$ \\
MaRB & 0.953 & $60.6 \%$ & $67.0 \%$ & $63.3 \%$ \\
MiRB & 0.909 & $70.5 \%$ & $61.7 \%$ & $66.8 \%$ \\
MBL & 0.895 & $62.1 \%$ & $62.8 \%$ & $62.4 \%$ \\
\hline
\end{tabular}


Table V. Sex prediction and equation using stepwise discriminant analysis.

\begin{tabular}{|c|c|c|c|c|c|c|c|}
\hline \multirow[t]{2}{*}{ Measurements } & \multicolumn{2}{|c|}{ Fisher coefficient } & \multirow[t]{2}{*}{ _ Wilks' } & \multirow{2}{*}{$\begin{array}{c}\mathrm{P}- \\
\text { value }\end{array}$} & \multicolumn{2}{|c|}{ Correct prediction } & \multirow[t]{2}{*}{ Mean correct prediction } \\
\hline & Males & Females & & & Males & Females & \\
\hline \multicolumn{8}{|l|}{ S tepwise } \\
\hline BG & 3.363 & 3.088 & 0.500 & 0.000 & $84.8 \%$ & $80.9 \%$ & $83.2 \%$ \\
\hline MRH & 2.264 & 2,017 & & & & & \\
\hline Constant & -233.715 & -193.672 & & & & & \\
\hline Function Males & \multicolumn{7}{|c|}{$-233.715+\left(3.363 \_\mathrm{BG}\right)+\left(2.264_{-} \mathrm{MRH}\right)$} \\
\hline Function Females & \multicolumn{7}{|c|}{$-366.300++\left(3.08 z_{-} \mathrm{BG}\right)+\left(2.017_{-} \mathrm{MRH}\right)$} \\
\hline \multicolumn{8}{|l|}{ Direct } \\
\hline $\mathrm{BC}$ & 2.733 & 2.640 & 0.491 & 0.000 & $87.9 \%$ & $80.9 \%$ & $85.0 \%$ \\
\hline $\mathrm{BG}$ & 1.567 & 1.306 & & & & & \\
\hline $\mathrm{BM}$ & 2.011 & 2.157 & & & & & \\
\hline MF-MB & 1.833 & 1.952 & & & & & \\
\hline MRH & 2.073 & 1.820 & & & & & \\
\hline MaRB & -0.306 & -0.265 & & & & & \\
\hline MiRB & $-1,481$ & -1.585 & & & & & \\
\hline MBL & $-1,863$ & 1.855 & & & & & \\
\hline Constant & -410.153 & -366.024 & & & & & \\
\hline Function male s & \multicolumn{7}{|c|}{$\begin{array}{l}410.153+(2.733 \times \mathrm{BC})+(1.567 \times \mathrm{BG})+(2.011 \times \mathrm{BM})+(1.833 \times \mathrm{MF}-\mathrm{MB})+(2.073 \times \mathrm{MRH})+(- \\
0.306 \times \mathrm{MaRB})+(-1.481 \times \mathrm{MiRB})+(-1.863 \times \mathrm{MBL})\end{array}$} \\
\hline Function females & \multicolumn{7}{|c|}{$\begin{array}{l}-366.024+(2.640 \times \mathrm{BC})+(1.306 \times \mathrm{BG})+(2.157 \times \mathrm{BM})+(1.952 \times \mathrm{MF}-\mathrm{MB})+(1.820 \times \mathrm{MRH})+(- \\
0.265 \times \mathrm{MaRB})+(-1.585 \times \mathrm{MiRB})+(1.855 \times \mathrm{MBL})\end{array}$} \\
\hline
\end{tabular}

\section{DISCUSSION}

Biological identification of sex is one of the most important techniques established by forensic science; it is essential in the recognition of individuals officially declared dead in situations such as mass disasters, atrocities and criminal investigations (de Oliveira et al., 2015; Schmeling et al., 2016).

The reliability and accuracy of sex prediction are directly dependent on the anatomical region of the remains (Mai et al., 2005). The mandible is originally bipartite, with each half developing absolutely independently (Testut \& Latarjet, 1968). It presents marked sexual dimorphism due to the development of the muscular-skeletal system, especially the chewing muscles attached to the mandible (Hu et al., 2006; Franklin et al., 2007). Different life styles and diets, as well as chewing habits and hormonal factors, affect the size and shape of the mandible (Hu et al.); this may result in differences in mandible morphology between different populations.

Various methods have been used to determine the accuracy of sexing by mandible analysis. Initially the simplest methods are applied, since before a more expensive or complex method is adopted, several variables must be considered, such as the conservation state of the skeleton, the clarity of the characteristics present and the precision required in each case (Krishan et al., 2016). Sex determination by analysis of morphological characteristics is quicker and easier, but it is more difficult to obtain a decision because the nutrition, occupation, descent and geographical origin of the individual must be considered (Kranioti et al., 2008). Nonetheless, in the hands of an expert observer non-metric assessment may offer great accuracy in determining sex (Krishan et al.). On the other hand, metric analysis is more accurate than visual analysis; however there are specific measurements for each population subject to trends in modern habits, so every population must be analysed separately (Dayal et al., 2008).

Sexual dimorphism in the mandible can be observed in individuals aged over 16 years (de Oliveira et al.), therefore only adult individuals aged over 18 years were included in this study. Only completely dentate mandibles were selected due to the morphological alterations which may result from tooth loss (Alves, 2009; Alves \& Cândido).

In the present study BG presented the greatest AUC and the best balance between sensitivity and specificity, corroborating previous studies in Brazilian populations (Gamba et al., 2016; Lopez-Capp et al., 2018). The mean values found for BG in the present study were similar to those found for individuals from Northern Thailand (Ongkana \& Sudwan) and for Black South Africans (Dayal et al.) (Table VI). Marinescu et al. (2013), in individuals from Romania, and Lopez-Capp et al. in Brazilian individuals, found that BG was the measurement which presented the greatest sexual dimorphism, corroborating the findings of the present study. 
In a study of individuals of European descent, the researchers observed that this measurement offers good sex prediction and can be used for sexing (Ilgüy et al., 2014). In discriminant analysis, we observed that this measurement presented the greatest mean correct prediction, with 80.5 $\%$, corroborating the findings of Lopez-Capp et al.

In an earlier study in a Brazilian population, the researchers observed that $\mathrm{BC}$ presented great sexual dimorphism (Gamba et al.; Lopez-Capp et al.); this was corroborated by the present study, where we found good sex determination (AUC: 0.778) and good accuracy (75.2 $\%$ ). In discriminant analysis we observed that this measurement achieved $69.9 \%$ mean correct prediction, higher than reported in another study also carried out on a Brazilian population (66\%) (Lopez-Capp et al.). The mean values found for $\mathrm{BC}$ in the present study were lower than those foundin Chinese (Dong et al., 2015) and Japanese populations (Ongkana \& Sudwan); similar to those reported for Brazilians (Lopez-Capp et al.) and Romanians (Marinescu et al.), and higher than reported in another study in a Brazilian population (Gamba et al.) (Table VI). In Chinese individuals, Dong et al. observed that this measurement presented great sexual dimorphism with an accuracy of $75 \%$ for males and $83.2 \%$ for females. For individuals of European descent on the other hand, it was observed that this measurement was of no assistance in determining sex (Ilgüy et al.).

de Oliveira et al. assessed sexual dimorphism and age from analysis of the MRH and reported that this measurement was reliable only for estimating the age of the individual, but presented no difference between sexes. However, other studies in Brazilian populations (Gamba et al.; Lopez-Capp et al.) observed that this measurement presented great sexual dimorphism; this corroborates the findings of the present study, where this measurement presented the second best AUC, good balance between sensitivity and specificity, and good accuracy. Discriminant analysis of this measurement in the present study showed a value of $76.1 \%$ mean correct prediction, higher than reported by Lopez-Capp et al. also in a Brazilian population, with values of $70 \%$ for the right side and $67 \%$ for the left. Values reported for Black South Africans (Dayal et al.), Brazilians (Gamba et al.) and Chinese (Dong et al.) were lower than found in our study. Similar values to those found in the present work were reported for individuals of European descent (Ilgüy et al.) and in another study on a Brazilian population (Lopez-Capp et al.). In populations from Japan (Ogawa et al.), Northern Thailand (Ongkana \& Sudwan) and Egypt (Kharoshah et al., 2010), the MRH values were higher than those found for the population analysed in our study (Table VI). In a study of individuals of European

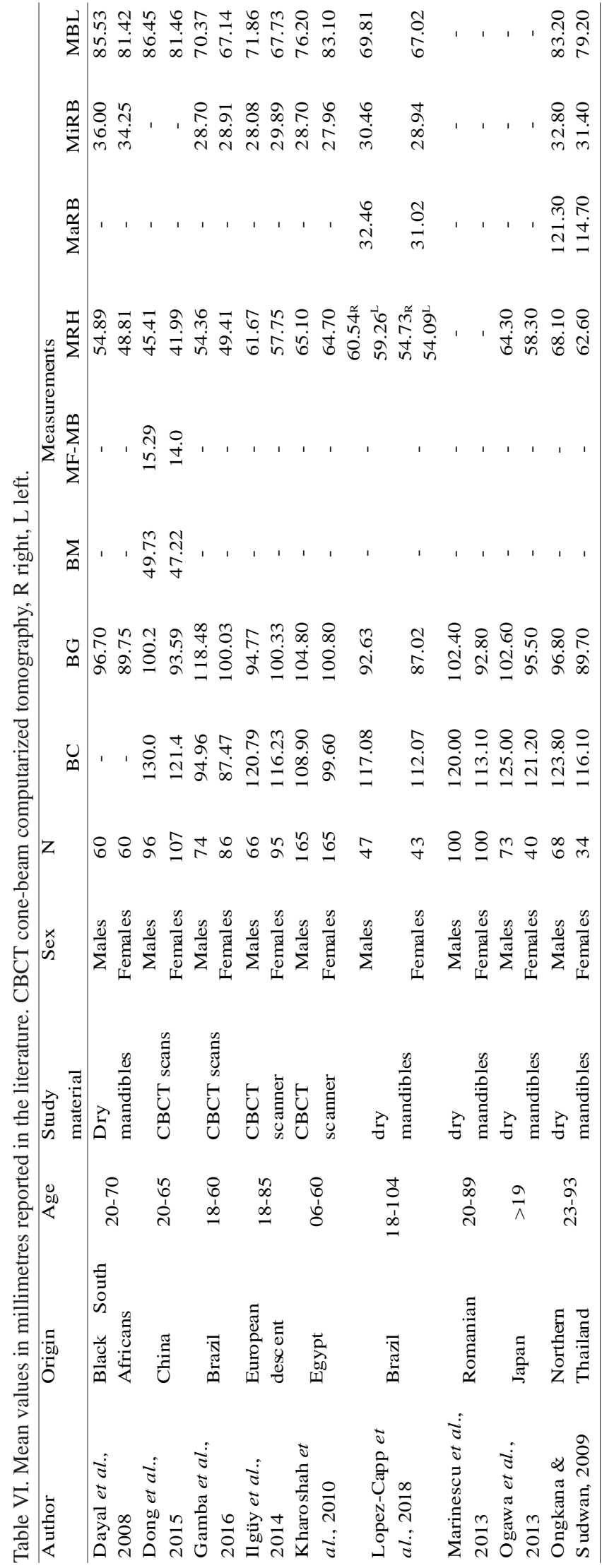


descent, the researchers observed that this measurement offers good sex prediction, corroborating the results of the present study (Ilgüy et al.).

In the present study, the other measurements taken (BM, MF-MB, MaRB, MiRB and MBL) presented AUC less than 0.700 , with accuracy varying between $76.6 \%$ and $68.7 \%$. The cut-off point presented in Table III can be used as a reference for determining sex from the mandible of unknown individuals. In discriminant analysis, BM, MF-MB, MaRB, MiRB and MBL presented sexual dimorphism with correct prediction varying between $66.8 \%$ and $55.8 \%$.

Direct discriminant analysis achieved $85 \%$ sex prediction, whereas stepwise analysis achieved $83.2 \%$ mean correct prediction using BG and $\mathrm{MRH}$, with better sex prediction in men than women. The correct sex prediction found in the present study agrees with previous studies. Dong et al. also found greater accuracy in sex prediction using the direct method $(84.2 \%)$ than the stepwise method $(83.3 \%)$. Lopez-Capp et al. found between $76 \%$ and $83 \%$ in an analysis of Brazilian macerated mandibles. In Egyptians, Kharoshah et al. found $83.9 \%$ correct prediction using MRH, $\mathrm{BC}, \mathrm{MiRB}$ and the gonial angle. In individuals of European descent, Ilgüy et al. found $83.2 \%$ predictive accuracy using MRH, MBL, BG and gonial angle. Similar values were also found for Romanians (Marinescu et al.), with $84 \%$ accuracy obtained from three measurements: chin height, BG and BC. In Black South Africans (Dayal et al.), accuracy of $85 \%$ was achieved using BG, MRH and total mandibular length. Slightly higher predictive accuracy than that found in our study was reported by Zheng et al. (2018) in individuals from north-eastern China, with mean correct prediction of $87.4 \%$. The accuracy was slightly higher for women (89\%) than men $(85.7 \%)$. They used 7 measurements in the final correct prediction: mandibular angle, area of mandibular foramen, BG, distance between left and right coronoid processes, minimum height, mandibular notch and palatal breadth. High accuracy of $95.1 \%$ was reported in another study in a Brazilian population (Gamba et al.), using MRH, $\mathrm{BC}, \mathrm{BG}$ and gonial angle. Values slightly lower than ours were reported by Carvalho et al. (2013), who found 78.13 $\%$ for females and $76.47 \%$ for males in an analysis of Brazilian mandibles using BG and MRH.

In the present study, all the measurements analysed presented sexual dimorphism, with greater values for men than for women. BG, MRH and BC presented better sex prediction in both discriminant analysis and the ROC curve; this corroborated previous studies also carried out in Brazilian populations (de Oliveira et al.; Gamba et al.; Lopez-Capp et al.).

\section{CONCLUSION}

The mandibles studied presented great sexual dimorphism under metric analysis. Of the measurements taken, BG, MRH and BC presented great accuracy in predicting sex, while $\mathrm{BM}$ presented the lowest predictive power. The measurements analysed in this study can be used in determining the sex of Brazilian individuals.

ALVES, N. \& DEANA, N. F. Predicción sexual mediante análisis métrica de mandíbulas maceradas de brasileños adultos. Int. J. Morphol., 37(4):1375-1381, 2019.

RESUMEN: En casos de desastres naturales, catástrofes o situaciones en las cuales los cuerpos son sometidos a altas temperaturas la identificación sexual queda más difícil, siendo necesaria la identificación de los individuos a partir de restos mortales. La mandíbula es un hueso muy resistente, que presenta gran dimorfismo sexual, pudiendo ser útil en la identificación forense. El objetivo de este estudio fue determinar la predicción sexual mediante el análisis métrico de mandíbulas maceradas de individuos brasileños adultos. Fueron analizadas 113 mandíbulas maceradas completamente dentadas de Brasileños adultos, siendo 47 mujeres y 66 hombres. Con un cáliper digital fueron evaluadas 8 medidas: amplitud bi-condilar (BC), amplitud bi-gonial (BG), amplitud entre forámenes mentonianos (BM), distancia entre el foramen mentoniano y la base de la mandíbula (MF-MB), altura de la rama mandibular (MRH), anchura máxima de la rama mandibular (MaRB), anchura mínima de la rama mandibular (MiRB) y longitud del cuerpo de la mandíbula (MBL). Para análisis estadístico se utilizó la prueba t para muestras independientes. Además se construyó una curva ROC. Se realizó análisis discriminante directo y por pasos. Se utilizó el software SPSS V.22, considerando umbral de significación de $5 \%$. Se observó que todas las medidas presentaron diferencias estadísticas entre sexos, siendo los valores medios encontrados para hombres mayores que los encontrados para mujeres. La BG fue la medida que presentó mayor área bajo la curva (AUC) y mayor predicción, seguido de la MRH y de la BC. La distancia BM fue la medida que presentó la menor AUC y menor predicción. La correcta predicción para el análisis discriminante directo alcanzó el $85 \%$ y por pasos alcanzó el $83.2 \%$ utilizándose las medidas BG y MRH. Las medidas analizadas en este estudio pueden ser utilizadas en el diagnóstico sexual de individuos Brasileños.

PALABRAS CLAVE: Mandíbula; Predicción sexual; Análisis discriminante.

\section{REFERENCES}

Alves, N. \& Cândido, P. Anatomia para o Curso de Odontologia Geral e Específica. $4^{\text {th }}$ ed. São Paulo, Editora Santos, 2016.

Alves, N. Study of the localization of the mental foramen in macerated mandibles with different degree of edentulism. Int. J. Odontostomat., 3(1):41-5, 2009. 
Angel, J. L. Colonial modern skeletal change in the U.S.A. Am. J. Phys. Anthropol., 45(3 pt. 2):723-35, 1976.

Carvalho, S. P.; Brito, L. M.; Paiva, L. A.; Bicudo, L. A.; Crosato, E. M. \& Oliveira, R. N. Validation of a physical anthropology methodology using mandibles for gender estimation in a Brazilian population. J. Appl. Oral Sci., 21(4):358-62, 2013.

Dayal, M. R.; Spocter, M. A. \& Bidmos, M. A. An assessment of sex using the skull of black South Africans by discriminant function analysis. Homo, 59(3):209-21, 2008.

de Oliveira, F. T.; Soares, M. Q.; Sarmento, V. A.; Rubira, C. M.; Lauris, J. R. \& Rubira-Bullen, I. R. Mandibular ramus length as an indicator of chronological age and sex. Int. J. Legal Med., 129(1):195-201, 2015.

Deana, N. F. \& Alves, N. Nonmetrical sexual dimorphism in mandibles of Brazilian individuals. Biomed. Res. (India), 28(9):4233-8, 2017.

Dong, H.; Deng, M.; Wang, W.; Zhang, J.; Mu, J. \& Zhu, G. Sexual dimorphism of the mandible in a contemporary Chinese Han population. Forensic Sci. Int., 255:9-15, 2015.

Evteev, A.; Cardini, A. L.; Morozova, I. \& O’Higgins, P. Extreme climate, rather than population history, explains mid-facial morphology of Northern Asians. Am. J. Phys. Anthropol., 153(3):449-62, 2014.

Franklin, D.; O'Higgins, P.; Oxnard, C. E. \& Dadour, I. Sexual dimorphism and population variation in the adult mandible : Forensic applications of geometric morphometrics. Forensic Sci. Med. Pathol., 3(1):15-22, 2007.

Gamba, T. de O.; Alves, M. C, \& Haiter-Neto, F. Mandibular sexual dimorphism analysis in CBCT scans. J. Forensic Leg. Med., 38:10610, 2016.

Hu, K. S.; Koh, K. S.; Han, S. H.; Shin, K. J. \& Kim, H. J. Sex determination using nonmetric characteristics of the mandible in Koreans. J. Forensic Sci., 51(6):1376-82, 2006.

Ilgüy, D.; Ilgüy, M.; Ersan, N.; Dölekolu, S. \& Fisekçiolu, E. Measurements of the foramen magnum and mandible in relation to sex using CBCT. J. Forensic Sci., 59(3):601-5, 2014.

Kemkes-Grottenthaler, A.; Löbig, F. \& Stock, F. Mandibular ramus flexure and gonial eversion as morphologic indicators of sex. Homo, 53(2):97$111,2002$.

Kharoshah, M. A.; Almadani, O.; Ghaleb, S. S.; Zaki, M. K.; \& Fattah, Y. A. Sexual dimorphism of the mandible in a modern Egyptian population. J. Forensic Leg. Med., 17(4):213-5, 2010.

Kranioti, E. F.; Is s can, M. Y. \& Michalodimitrakis, M. Craniometric analysis of the modern Cretan population. Forensic Sci. Int., 180(2-3):110.e15, 2008.

Krishan, K.; Chatterjee, P. M.; Kanchan, T.; Kaur, S.; Baryah, N.; \& Singh, R. K. A review of sex estimation techniques during examination of skeletal remains in forensic anthropology casework. Forensic Sci. Int., 261:165.e1-8, 2016.

Krogman, W. \& Iscan, M. The Human Skeleton in Forensic Medicine. Springfield, Illinois, Charles C. Thomas, 1986.

Lopez-Capp, T. T.; Rynn, C.; Wilkinson, C.; de Paiva, L. A. S.; MichelCrosato, E. \& Biazevic, M. G. H. Discriminant analysis of mandibular measurements for the estimation of sex in a modern Brazilian sample. Int. J. Legal Med, 132(3):843-51, 2018.

Mai, L. L.; Owl, M. Y. \& Kersting, M. P. The Cambridge Dictionary of Human Biology and Evolution. Cambridge, Cambridge University Press, 2005.

Marinescu, M.; Panaitescu, V. \& Rosu, M. Sex determination in Romanian mandible using discriminant function analysis: Comparative results of a time-efficient method. Rom. J. Leg. Med., 21(4):305-8, 2013.

Oettlé, A. C.; Pretorius, E. \& Steyn, M. Geometric morphometric analysis of the use of mandibular gonial eversion in sex determination. Homo, 60(1):29-43, 2009.

Ogawa, Y.; Imaizumi, K.; Miyasaka, S. \& Yoshino, M. Discriminant functions for sex estimation of modern Japanese skulls. J. Forensic Leg. Med., 20(4):234-8, 2013.

Ongkana, N. \& Sudwan, P. Gender difference in Thai mandibles using metric analysis. Chiang Mai Med. J., 48(2):43-8, 2009.
Rogers, T. L. Determining the sex of human remains through cranial morphology. J. Forensic Sci., 50(3):493-500, 2005.

Saini, V.; Srivastava, R.; Rai, R. K.; Shamal, S. N.; Singh, T. B. \& Tripathi, S. K. Mandibular ramus: an indicator for sex in fragmentary mandible. J. Forensic Sci., 56 Suppl. 1:S13-6, 2011.

Scheuer, L. Application of osteology to forensic medicine. Clin. Anat., 15(4):297-312, 2002.

Schmeling, A.; Dettmeyer, R.; Rudolf, E.; Vieth, V. \& Geserick, G. Forensic age estimation. Dtsch. Arztebl. Int., 113(4):44-50, 2016.

Sharma, M.; Gorea, R. K.; Gorea, A. \& Abuderman, A. A morphometric study of the human mandible in the Indian population for sex determination. Egypt. J. Forensic Sci., 6(2):165-9, 2016.

Testut, L. \& Latarjet, A. Compendio de Anatomía Descriptiva. $22^{\text {nd }}$ ed. Barcelona, Salvat Editores S. A., 1968.

Zheng, J.; Ni, S.; Wang, Y.; Zhang, B.; Teng, Y. \& Jiang, S. Sex determination of Han adults in Northeast China using cone beam computer tomography. Forensic Sci. Int., 289:450.e1-450.e7, 2018.

\author{
Corresponding author: \\ Naira Figueiredo Deana \\ Universidad de La Frontera \\ Avda. Francisco Salazar 1145 \\ PO-BOX 54-D \\ Temuco \\ CHILE
}

Email: n.figueiredo01@ufromail.cl

Received: 24-01-2019

Accepted: 05-06-2019 